\title{
Growing Productivity without Growing Wages: The Micro-Level Anatomy of the Aggregate Labor Share Decline*
}

\author{
Matthias Kehrig ${ }^{\dagger}$ and Nicolas Vincent $\ddagger$
}

First version: November 2015

This version: February 14, 2017

\begin{abstract}
The aggregate labor share in U.S. manufacturing declined dramatically over the last three decades: Since the mid-1980's, the compensation for labor declined from $63 \%$ to $42 \%$ of value added which is unseen in any other sector of the U.S. economy. The labor share of the typical U.S. manufacturing plants, in contrast, rose by $5 \%$. We document that reallocation of production towards "hyper-productive plants" contributes two thirds of the decline while the remaining one third are caused by exit of high-labor share plants. Plants that account for the majority of production by the late 2000's arrive at a low labor share by gradually increasing value added by a factor of three while keeping employment and compensation unchanged. Other than this output response, these low-labor share plants look very similar to their peers along almost all other characteristics such as equipment investment, exposure to trade or whether they are located in right-to-work states. Labor share decline explanations that focus on the role of equipmentembodied technical change, unions or international trade only therefore seem limited. Based on novel empirical evidence, we consider alternative explanations.
\end{abstract}

Keywords: Labor Share, Labor Productivity, Organisation of Markets, Firm Size Distribution. JEL classification: E2, L1, L2, L6, O4.

\footnotetext{
*We would like to thank Nick Bloom, Pete Klenow, Chad Jones, Luigi Pistaferri, Steve Davis and John Cochrane and participants at Stanford, Mannheim, the Cambridge-INET conference for helpful comments. All errors are our own. Financial support from the Fritz Thyssen Stiftung is gratefully acknowledged.

${ }^{\dagger}$ Duke University, Department of Economics, Box 90097, Durham, NC 27708, matthias.kehrig@duke.edu

${ }^{\ddagger}$ HEC Montréal, Department of Applied Economics, 3000 Côte-Sainte-Catherine, Montréal, Quebec H3T 2A7, Canada. Email: nicolas.vincent@hec.ca. The latest version of this paper can be downloaded at http://ssrn.com/abstract $=2916517$
} 